\title{
Right ventricular local longitudinal curvature as a marker and predictor for pulmonary valve replacement surgery outcome: An initial study based on preoperative and postoperative cardiac magnetic resonance data from patients with repaired tetralogy of Fallot
}

\author{
Dalin Tang, PhD, ${ }^{\mathrm{a}, \mathrm{b}}$ Chun Yang, MS, ${ }^{\mathrm{b}, \mathrm{c}}$ Tal Geva, MD, ${ }^{\mathrm{d}, \mathrm{e}}$ and Pedro J. del Nido, MD, ${ }^{\mathrm{f,g}}$ Worcester and \\ Boston, Mass; and Nanjing and Beijing, China
}

Patients with repaired tetralogy of Fallot, a congenital heart defect that includes a ventricular septal defect and severe right ventricular (RV) outflow obstruction, account for most cases of late-onset RV failure. The current surgical approach, which includes pulmonary valve replacement (PVR), has yielded mixed results, with many patients not recovering RV function after PVR with or without concomitant RV remodeling surgery. ${ }^{1}$ For patients with tetralogy of Fallot who need PVR surgery, surgical intervention such as

\footnotetext{
From the School of Biological Sciences and Medical Engineering, ${ }^{\text {a }}$ Southeast University, Nanjing, China; Mathematical Sciences Department, ${ }^{\text {b }}$ Worcester Polytechnic Institute, Worcester, Mass; China United Network Communications Co, Ltd, ${ }^{\mathrm{c}}$ Beijing, China; the Department of Cardiology, ${ }^{\mathrm{d}}$ Children's Hospital Boston, Boston, Mass; the Department of Pediatrics, ${ }^{e}$ Harvard Medical School, Boston, Mass; the Department of Cardiac Surgery, ${ }^{f}$ Children's Hospital Boston, Boston, Mass; and the Department of Surgery, ${ }^{\mathrm{g}}$ Harvard Medical School, Boston, Mass.

Supported in part by National Institutes of Health grants 1R01-HL 089269 (to D.T., T.G., P.J.d.N.), HL 63095 (to P.J.d.N.), and NHLBI 5P50HL074734 (to T.G.). C.Y.'s research supported in part by the National Sciences Foundation of China, 11171030.

Disclosures: Authors have nothing to disclose with regard to commercial support. Received for publication March 30, 2013; revisions received Aug 1, 2013; accepted for publication Aug 15, 2013; available ahead of print Oct 7, 2013.

Address for reprints: Dalin Tang, PhD, Mathematical Sciences Department,

Worcester Polytechnic Institute, Worcester, MA 01609 (E-mail: dtang@wpi.edu). J Thorac Cardiovasc Surg 2014;147:537-8 $0022-5223 / \$ 36.00$

Copyright $(C) 2014$ by The American Association for Thoracic Surgery http://dx.doi.org/10.1016/j.jtcvs.2013.08.054
}

scar tissue resection and anterior wall RV remodeling have been proposed to improve RV functional recovery. ${ }^{2}$ Although our patient-specific models supported the RV remodeling approach, ${ }^{3}$ data from our clinical trial showed only modest improvement in RV ejection fraction (RVEF) at 6-month postoperative follow-up $(-2 \% \pm 7 \%$ in the PVR-alone group $[\mathrm{n}=34]$ vs $-1 \% \pm 7 \%$ in the PVR with RV remodeling group $[\mathrm{n}=30] ; P=.38){ }^{4}$

In search for indicators that can be used to identify patients with better outcomes after PVR, 10 patients were randomly selected from our clinical trial data pool (with institutional review board approval and consent obtained) to conduct this morphologic study.

\section{MATERIALS AND METHODS}

Our data-acquisition methods have been previously described. ${ }^{3,5}$ Table 1 gives the RVEF data from the 10 patients with a 6-month follow-up cardiac magnetic resonance scan after PVR. The 10 patients were divided into 2 groups on the basis of change in RVEF from preoperative to postoperative values. Group 1 consisted of the 5 patients with the worst decline in RVEF, whereas group 2 consisted of the 5 patients with the least decline or with improvement.

Patients' preoperative end-diastolic and end-systolic RV geometries were used for our morphologic study. For each cardiac magnetic resonance data set (11-14 slices [short-axis cross sections] for the end-diastolic set; 9-12 slices for the end-systolic set), we divided each slice into 4 quarters of equal inner wall circumferential length. RV wall thickness, circumferential curvature (C-curvature), and longitudinal curvature (L-curvature) were

TABLE 1. Right ventricular ejection fraction data from the 10 patients studied

\begin{tabular}{|c|c|c|c|c|c|c|c|c|c|}
\hline \multirow[b]{2}{*}{ Patient } & \multirow[b]{2}{*}{ Sex } & \multirow[b]{2}{*}{ Age (y) } & \multicolumn{3}{|c|}{ Preoperative } & \multicolumn{3}{|c|}{ Postoperative } & \multirow[b]{2}{*}{ EF change $(\%)$} \\
\hline & & & EDV (mL) & ESV (mL) & EF (\%) & EDV $(\mathbf{m L})$ & ESV (mL) & EF (\%) & \\
\hline 1 & $\mathrm{~F}$ & 56.9 & 385.08 & 184.58 & 52.07 & 216.36 & 142.62 & 34.08 & -17.99 \\
\hline 2 & M & 43.5 & 665.06 & 464.05 & 30.22 & 390.99 & 332.35 & 15 & -15.22 \\
\hline 3 & M & 11.6 & 204.17 & 121.26 & 40.61 & 156.28 & 105.96 & 32.2 & -8.41 \\
\hline 4 & M & 23.1 & 424.18 & 250.18 & 41.02 & 145.94 & 97.95 & 32.88 & -8.14 \\
\hline 5 & M & 54.1 & 334.77 & 170.76 & 48.99 & 306.2 & 177.62 & 41.99 & -7 \\
\hline 6 & $\mathrm{~F}$ & 38.5 & 328.79 & 195.97 & 40.4 & 168.32 & 105.96 & 37.05 & -3.35 \\
\hline 7 & M & 50.0 & 364.57 & 239.51 & 34.3 & 220 & 150.91 & 31.4 & -2.9 \\
\hline 8 & M & 47.7 & 408.76 & 254.79 & 37.67 & 327.21 & 212.32 & 35.11 & -2.56 \\
\hline 9 & M & 22.5 & 406.91 & 254.49 & 37.46 & 188.3 & 114.96 & 38.95 & 1.49 \\
\hline 10 & $\mathrm{~F}$ & 42.0 & 323.3 & 177.84 & 44.99 & 222.23 & 113.29 & 49.02 & 4.03 \\
\hline
\end{tabular}

Group 1 (patients 1-5) showed mean change in right ventricular ejection fraction from before to after pulmonary valve replacement of $-11.4 \% \pm 4.9 \%$; group 2 (patients $6-10$ ) showed mean change in right ventricular ejection fraction from before to after pulmonary valve replacement of $-0.66 \% \pm 3.3 \%(P=.005)$. $F$, Female; $M$, male; $E D V$, end-diastolic volume; $E S V$, end-systolic volume; $E F$, ejection fraction. 
TABLE 2. Comparison of right ventricular volume and quarter mean values of ventricle wall thickness, circumferential curvature, and longitudinal curvature between groups 1 and 2 showing that longitudinal curvature could be a potential predictor of outcome after pulmonary valve replacement

\begin{tabular}{|c|c|c|c|c|c|c|c|c|c|c|}
\hline & \multicolumn{5}{|c|}{ End-diastole } & \multicolumn{5}{|c|}{ End-systole } \\
\hline & Qts & WT (cm) & C-Cur $\left(\mathrm{cm}^{-1}\right)$ & L-Cur $\left(\mathrm{cm}^{-1}\right)$ & Vol (mL) & Qts & WT (cm) & C-Cur $\left(\mathrm{cm}^{-1}\right)$ & L-Cur $\left(\mathrm{cm}^{-1}\right)$ & Vol (mL) \\
\hline \multicolumn{11}{|l|}{ Group 1} \\
\hline Mean & 248 & 0.4253 & 0.4610 & 0.5330 & 402.7 & 200 & 0.5550 & 0.5084 & 0.5763 & 238.2 \\
\hline $\mathrm{SD}$ & & 0.2224 & 0.4030 & 0.4007 & 168.5 & & 0.2381 & 0.3251 & 0.3675 & 134.4 \\
\hline \multicolumn{11}{|l|}{ Group 2} \\
\hline Mean & 232 & 0.3973 & 0.4642 & 0.7278 & 366.5 & 204 & 0.4902 & 0.5743 & 0.7308 & 224.5 \\
\hline $\mathrm{SD}$ & & 0.1894 & 0.3102 & 0.7539 & 40.96 & & 0.2685 & 0.4669 & 0.7493 & 35.47 \\
\hline$P$ value & & .1398 & .9232 & .0004 & .653 & & .0107 & .1009 & .0091 & .832 \\
\hline
\end{tabular}

Qts, Quarters; WT, wall thickness; C-Cur, circumferential curvature; $L$-Cur, longitudinal curvature; Vol, volume; $S D$, standard deviation.

calculated at all nodal points (100 points/slice, 25 points/quarter). The "quarter" RV wall thickness and the C-and L-curvatures were obtained by taking averages of those quantities across the 25 points for each quarter and saved for analysis. The RV wall thickness and C- and L-curvature values on those quarters from the 2 patient groups were compared to see whether there were any statistically significant differences.

C-curvature $\left(\mathrm{k}_{\mathrm{c}}\right)$ at each point on an $\mathrm{RV}$ inner contour was calculated according to the following equation:

$$
k_{c}=\frac{x^{\prime} y^{\prime \prime}-x^{\prime \prime} y^{\prime}}{\left(x^{\prime 2}+y^{\prime 2}\right)^{3 / 2}}
$$

where the contour was a planar curve, $x$ and $y$ are treated as the function of arc, and the derivatives were evaluated with neighboring points on the contour.

L-curvature $(\mathrm{k})$ at each point on an RV inner contour was calculated according to the following equation:

$k=\frac{\sqrt{\left(z^{\prime \prime}(t) y^{\prime}(t)-y^{\prime \prime}(t) z^{\prime}(t)\right)^{2}+\left(x^{\prime \prime}(t) z^{\prime}(t)-z^{\prime \prime}(t) x^{\prime}(t)\right)^{2}+\left(y^{\prime \prime}(t) x^{\prime}(t)-x^{\prime \prime}(t) y^{\prime}(t)\right)^{2}}}{\left(x^{\prime 2}(t)+y^{\prime 2}(t) z^{\prime 2}(t)\right)^{3 / 2}}$

where the longitudinal curve $(X)$ was given by $\mathrm{X}=(x(t), y(t), z(t))$ and the derivatives were evaluated with points from neighboring slices vertically below and above the point being considered. Interpolations were used to obtain vertical neighboring points from the neighboring slices. One-sided formulas were used for the top and bottom slices.

For end-diastolic data, there were 248 quarters from group 1 and 232 from group 2. For end-systolic data, there were 200 quarters from group 1 and 204 from group 2. Student $t$ test was used to compare our data from the 2 groups.

\section{RESULTS}

Table 2 shows the comparison of wall thickness, C-curvature, $\mathrm{L}$-curvature, and RV volume between the 2 groups under end-diastolic and end-systolic conditions. Comparison of wall thickness, $\mathrm{C}$-curvature and $\mathrm{RV}$ volume from the 2 groups under both end-diastolic and end-systolic conditions did not reveal statistically significant differences; however, the mean L-curvatures from group 2 at end-diastole (maximum
$\mathrm{RV}$ volume) and end-systole (minimum RV volume) were 0.7278 and 0.7308 , respectively, $36.5 \%(P=.0004)$ and $26.8 \%(P=.0091)$ higher than the respective values from group 1 . The difference was statistically significant.

\section{DISCUSSION}

This initial study indicated that the RV L-curvature may be used as a marker or predictor for PVR surgical outcome in patients with repaired tetralogy of Fallot. The patients with greater RV L-curvature (which is the mean of local L-curvatures at all nodal points) may have better outcomes after PVR surgery. Another observation was that the L-curvatures of group 2 patients were much greater than the $\mathrm{C}$-curvatures relative to the same ratios from group 1 patients, which may indicate that RVs with greater L-curvatures (more "curved" in the longitudinal direction) could have better outcomes after PVR surgery. This could be a consideration in designing new surgical targets for RV remodeling. Large-scale studies are needed to verify these findings.

\section{References}

1. Therrien J, Siu SC, McLaughlin PR, Liu PP, Williams WG, Webb GD. Pulmonary valve replacement in adults late after repair of tetralogy of Fallot: are we operating too late? J Am Coll Cardiol. 2000;36:1670-5.

2. del Nido PJ. Surgical management of right ventricular dysfunction late after repair of tetralogy of Fallot: right ventricular remodeling surgery. Semin Thorac Cardiovasc Surg Pediatr Card Surg Annu 2006;29-34

3. Tang D, Yang C, Geva T, del Nido PJ. Image-based patient-specific ventricle models with fluid-structure interaction for cardiac function assessment and surgical design optimization. Prog Pediatr Cardiol. 2010;30:51-62.

4. Geva T, Gauvreau K, Powell AJ, Cecchin F, Rhodes J, Geva J, et al. Randomized trial of pulmonary valve replacement with and without right ventricular remodeling surgery. Circulation. 2010;122(11 Suppl):S201-8.

5. Yang C, Tang D, Geva T, Rathod R, Yamauchi H, Gooty V, et al. Using contracting band to improve right ventricle ejection fraction for patients with repaired tetralogy of Fallot: a modeling study using patient-specific CMR-based 2-layer anisotropic models of human right and left ventricles. J Thorac Cardiovasc Surg. 2013;145:285-93.e1-2. 